\title{
Experimental and Numerical Considerations of Air Entrainment Process of Diesel Spray
}

\author{
Takahide Aoyagi ${ }^{1}$, Elsayed Abdelhameed ${ }^{1,2}$, Daisuke Tsuru ${ }^{1}$, Hiroshi Tashima*1 \\ ${ }^{1}$ Interdisciplinary Graduate School of Engineering Sciences, Kyushu University, Japan \\ ${ }^{2}$ Mechanical Engineering Department, Faculty of Engineering, Kafrelsheikh University, \\ Kafrelsheikh 33516, Egypt \\ ${ }^{*}$ Corresponding author email : tasima@ence.kyushu-u.ac.jp
}

\begin{abstract}
Although several efforts have been done to capture the air entrainment flux into a diesel spray, determinative results are still yet to come because of difficulty in simultaneous measurement of the spray profile and the velocity fields around the spray. Moreover, it has been obscure whether droplet dispersion effect is dominating or not on the spray air entrainment. In the study, properties such as penetration length, cone angle, and ambient velocity field around a diesel spray were investigated in detail using a constant volume chamber (CVC, bore $150 \mathrm{~mm}$, height $350 \mathrm{~mm}$ )) and a dynamic 2D PIV system. The measurement results of the velocity field around the spray showed that the passive entrainment air flux induced by spray motion was much less than the active entrainment along with spray development or droplet dispersion. These results were compared with provisional simulation results of a commercial CFD code to confirm the share ratio of the two entrainments, and also to investigate the behaviors of a liquid spray in entraining the ambient gas at different locations in the spray body by visualizing the entrainment process of virtual marker gas injected on the spray trajectory.
\end{abstract}

\section{Keywords}

Diesel spray, Air entrainment, PIV, DDM.

\section{Introduction}

Even though the EV shift movement suddenly emerges in automotive fields worldwide, diesel engines keep their status as one of the most efficient power sources especially in industrial and marine propulsive fields. Further improvements should be made to better their thermal efficiency and to adopt GHG-free fuels like ammonia and $\mathrm{H}_{2}$. The diesel combustion process is thought to reflect the mixture formation and the mixture distribution in a spray, therefore fuel injection is surely one of the main factors influencing the combustion process in diesel engines and numerous investigations have been carried out on the developing process of a diesel spray [3].

In the early stages of the studies, an approximation to a steady gas jet was applied to a diesel spray. Wakuri et al. [6] proposed the momentum theory of a diesel spray. In the theory, a spray turns out to be a mixture jet of ambient gas and diesel fuel immediately after the high-pressure fuel injection into a high-density ambience. Hiroyasu et al. [7] successfully formulated various spray characteristics based on their experimental works.

Nowadays, several in-situ measurement technics have been developed to capture the inner spray structure. Xia et al. [2] experimentally studied the injection and the atomization of sprays in a marine diesel under various conditions. Kannaiyan et al. [4] studied the effect of the nanoparticles on the spray behavior under atmospheric conditions. Yu et al. [5] investigated the atomization of the diesel spray and characteristics of the combustion under injection pressure rating $350 \mathrm{MPa}$ using a constant-volume chamber containing the mixture of hydrogen and air inside. It would be easy to understand that the spray quality is largely affected by the 
air entrainment into a spray body. However, the instantaneous entrainment flux has not been well investigated because of the difficulty in determining the spray boundary and the velocity fields around the spray at the same time. In this research, air entrainment process into a diesel spray was investigated in detail through the observation of the developing process of a single diesel spray in a constant-volume chamber (CVC). The instantaneous entrainment mass into the spray body was determined based on the simultaneous measurements of an influx field around the spray by dynamic Particle Image Velocimetry (PIV) using a high-repetition pulse laser and of the spray contour information from the Mie scattering light of the spray droplets. Additional investigation was done by heating the ambient air in the VCVC to examine the effects of droplet evaporation and by predicting the spray development on 3D CFD to simulate the air entraining process numerically.

\section{Experimental equipment and conditions}

Figure 1 illustrates a constant volume chamber (CVC) used for the spray measurement in this study. The inner capacity of CVC is a cylindrical shape of $150 \mathrm{~mm}$ in diameter and $350 \mathrm{~mm}$ in height. A coaxial heater surrounds the inner volume and consists of an inner winding wire and an outer thermal insulator. A single-hole common-rail-type injector was mounted in a top lid of CVC and its nozzle hole $(\varnothing 0.16 \mathrm{~mm})$ aims at the perpendicular center axis of CVC. To observe the spray development from the nozzle hole exit, two opposing quartz windows locate in the upper half of CVC and they are $60 \mathrm{~mm}$ in width and $160 \mathrm{~mm}$ in height. One more quartz window $((\varnothing 70 \mathrm{~mm}))$ is installed on the bottom of CVC for the incidence of PIV laser sheet. An additional laser sheet is introduced from the top lid of CVC through a rod lens to enhance the PIV data rate near the spray root area.

Table 1 summarizes experimental conditions of the fuel injection and the inner atmosphere of CVC. Thanks to the high flexibility of CVC in setting ambient temperature and pressure separately, the ambient temperature was set to near non-evaporation level $(301 \mathrm{~K})$ and to active evaporation level $(823 \mathrm{~K})$ with the ambient density, one of the most important indexes for spray atomization, fixed at three levels by adjusting the ambient pressure one by one.

Table 2 shows main specifications of applied PIV system. Only in case of the high ambient temperature, the air replaced with nitrogen gas.

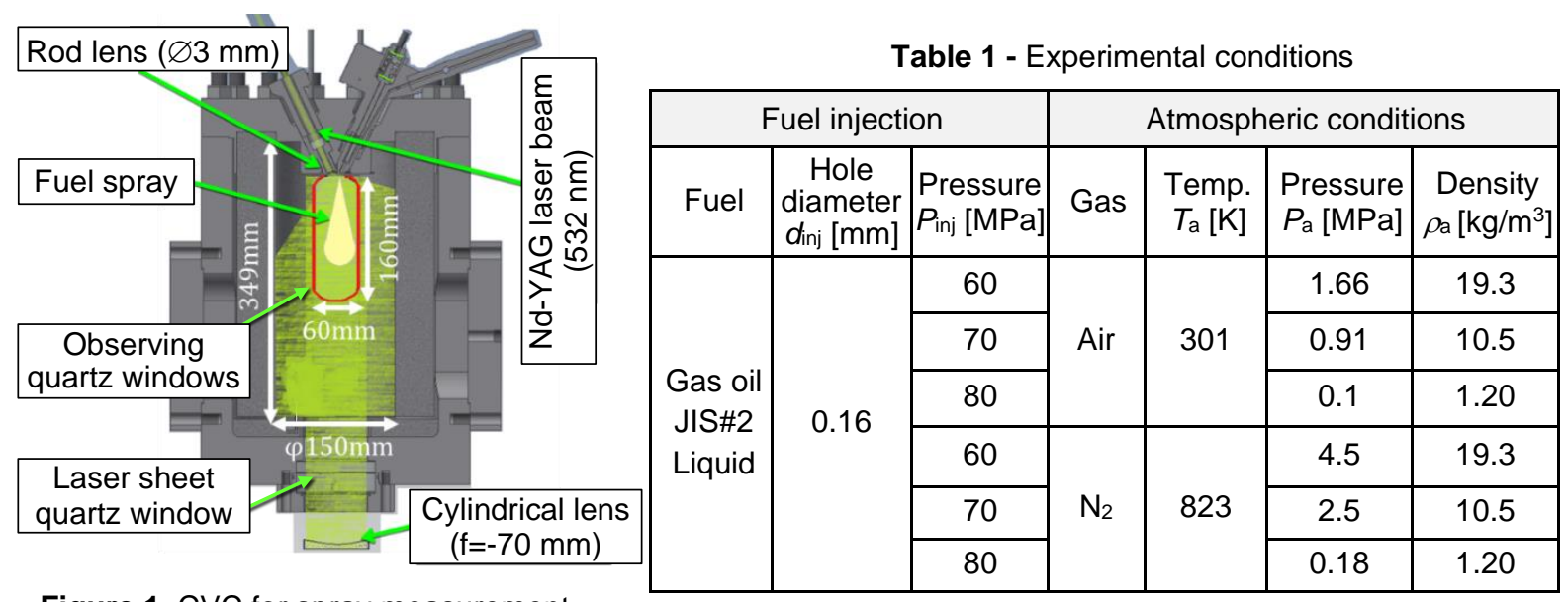

Figure 1. CVC for spray measurement

\section{Entrainment calculation method}

Figure 2 shows the schematic classification of entraining sections over a spray body proposed by Zhu et al [4]. From a nozzle tip, they line up in order of entraining section (ES), a recirculating section (RS), and a capturing section (CS). ES corresponds to a conventional 
entrainment along with a near conical spray part, CS is roughly equal to a spray tip pushing the confronting ambient gas aside, and RS is a transition part between the two. As shown in the figure, velocity filed around a spray body acquired by PIV measurement and boundary data based on some kind of a spray image should be combined in order to calculate the entrainment mass flux into the spray from each section. In the study, the entraining mass flux and the entraining velocity component is defined to be positive, and the pushing mass flux and the pushing velocity component is as negative. This means strong negative flux would be expected in CS and moderate positive flux in ES. The borders between these three sections are somewhat arbitrary because of the lack of clear definition. In this study, the boundary between CS and RS was set on $80 \%$ point of the spray penetration, and the boundary between $\mathrm{RS}$ and ES was neglected and all the velocity was counted into spray air entrainment.

Table 2 - Specifications and configurations of PIV system

\begin{tabular}{|l|c||c|c|}
\hline \multicolumn{2}{|c||}{ High-speed photographing for PIV } & \multicolumn{2}{c|}{ High frequency light source for PIV } \\
\hline High-speed camera & SA-Z Monochrome (Photoron) & Nd:YAG pulse laser & LDP-100MQG (Lee Laser) \\
\hline Frame rate & $20,000 \mathrm{fps}$ & Wavelength & $532 \mathrm{~nm}$ \\
\hline Resolution & $1,024 \times 512$ pixels & Pulse width & $200 \mathrm{~ns}$ \\
\hline Exposure time & $23.39 \mu \mathrm{s}$ & Pulse energy & $2.0 \mathrm{~mJ} / \mathrm{pulse}$ \\
\hline Lenses & $\begin{array}{c}\text { Micro NIKKOR } 105 \mathrm{~mm}, \mathrm{~F} 2.8 \\
+2.0-p o w e r \text { teleconverter }\end{array}$ & Frequency & $\begin{array}{l}20 \mathrm{kHz}(\Delta t=50 \mu \mathrm{s}) \text { for spray } \\
40 \mathrm{kHz}(\Delta t=25 \mu \mathrm{s}) \text { for gas jet }\end{array}$ \\
\hline \multicolumn{2}{|c||}{ Suspending tracers in CVC for PIV } & Timing controller & LC880 (Labsmith) \\
\hline Type & $\begin{array}{c}\text { Godd Ball, B-5C } \\
\text { (Suzuki Yushi Industrial Co., Ltd) }\end{array}$ & PIV software & Koncert II (Seika Corporation) \\
\hline Material & Spherical hollow SiO 2 particle & Algorithm & Reflexive cross-correlation method \\
\hline Mean diameter & $2.0 ~ 2.5 \mu \mathrm{m}$ & Window size & $16 \times 16$ pixels \\
\hline Bulk density & $180 ~ 450 \mathrm{~kg} / \mathrm{m}^{3}$ & Overlap & $50 \%$ \\
\hline
\end{tabular}

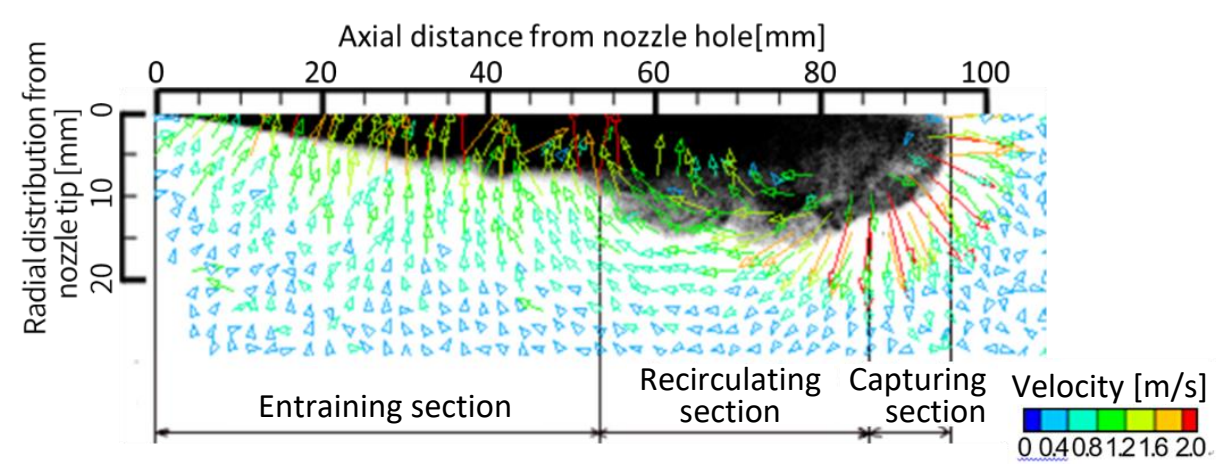

Figure 2. Three sections relating spray air entrainment (Zhu et al, 2012) $P_{\text {inj, }}=300 \mathrm{MPa}, \rho_{\mathrm{a}}=11 \mathrm{~kg} / \mathrm{m}^{3}, d_{\text {inj }}=0.08 \mathrm{~mm}, t=2.2 \mathrm{~ms}$ ASOI

\section{Experimental results and discussions}

Figure 3 is spray images by Mie scattering laser light from spray droplets. The figure shows the effects of ambient and injection conditions on spray development process. Slight asymmetric spray profile can be pointed out around the spray center axis since the additional laser sheet illuminates the vicinity of the nozzle hole from the bottom left side in the figure. Under near atmospheric density, the spray was fast enough to penetrate through the whole field of view at $1 \mathrm{~ms} \mathrm{ASOI}$ and the spray tip was so sharp compared with from a typical round ice-ball shape and the spreading spray cone angle was so narrow compared with high density cases. It was also found that the spreading cone angle of the liquid part of the spray decreased 
with ambient temperature. Considering the higher injection pressure in the high temperature case, the spray penetration length seemed to decrease with droplet evaporation, which was evident in the $3 \mathrm{~ms}$ ASOI image on the bottom.
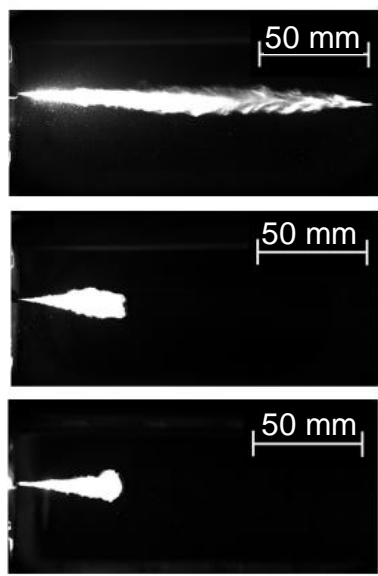

$1 \mathrm{~ms}$
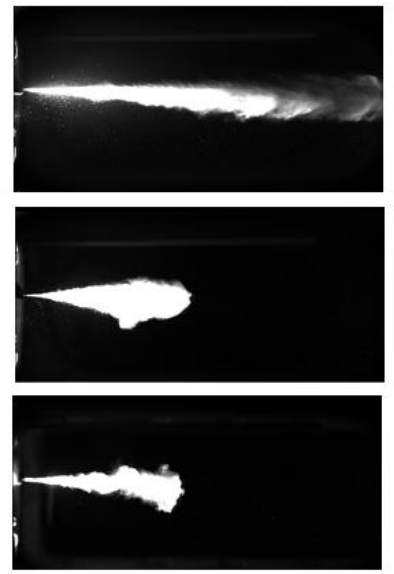

$2 \mathrm{~ms}$

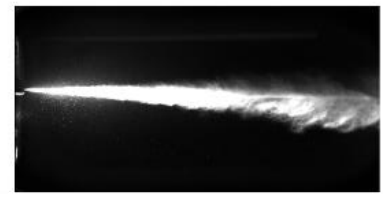

$P_{\text {inj }}=60 \mathrm{MPa}$ $\rho$ inj $=1.3 \mathrm{~kg} / \mathrm{m}^{3}$ $T_{\mathrm{a}}=301 \mathrm{~K}$

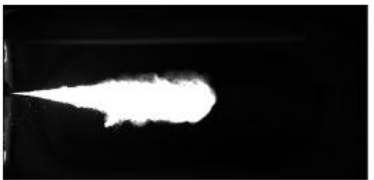

$P_{\text {inj }}=60 \mathrm{MPa}$ $\rho$ inj $=19.3 \mathrm{~kg} / \mathrm{m}^{3}$ $T_{\mathrm{a}}=301 \mathrm{~K}$

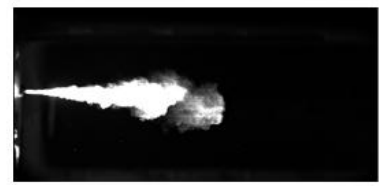

$3 \mathrm{~ms}$

Elapsed time after start of injection

Figure 3 Spray development process under different ambient and injection conditions

Figure $\mathbf{4 a}$ and $\mathbf{4 b}$ show the spray penetration and the spray cone angle under various conditions of injection pressures, ambient densities, ambient temperatures. Figure $\mathbf{4 a}$ represents the diesel spray penetration versus time at $301 \mathrm{~K}$, the higher the density the less the penetration due to the higher drag force of the ambient. The spray penetration reached $165 \mathrm{~mm}$ length at (1, 6 and 9) $\mathrm{ms}$ ASOI at (1.2, 10.5 and 19.3) $\mathrm{kg} / \mathrm{m}^{3}$ ambient density, respectively. In case of the high ambient temperature, from Figure 4 エラー! 参照元が見つか りまん。b, the spray penetration reached $165 \mathrm{~mm}$ length at $(1,9$ and 11) ms ASOI at the three ambient densities. Increasing the ambient temperature led to a decrease in the penetration which can be due to the higher evaporation rate on the tip of the spray. The spray penetration followed a known tendency of time proportional to about $0.3 \mathrm{~ms} \mathrm{ASOI}$ and then proportional to the square root, not limited to the evaporation non-evaporation condition, except for the low atmospheric density condition.

It can be noticed that the spray angle is directly proportional with the ambient density. While the spray penetration decreases with ambient density increase. This can be due to the air-fuel mixture containing fuel droplets exchanges momentum with the surrounding fluid in a highdensity air in a quasi-steady state where the injection rate is stable. Moreover, at the same injection, the higher the ambient temperature the larger the cone angle.
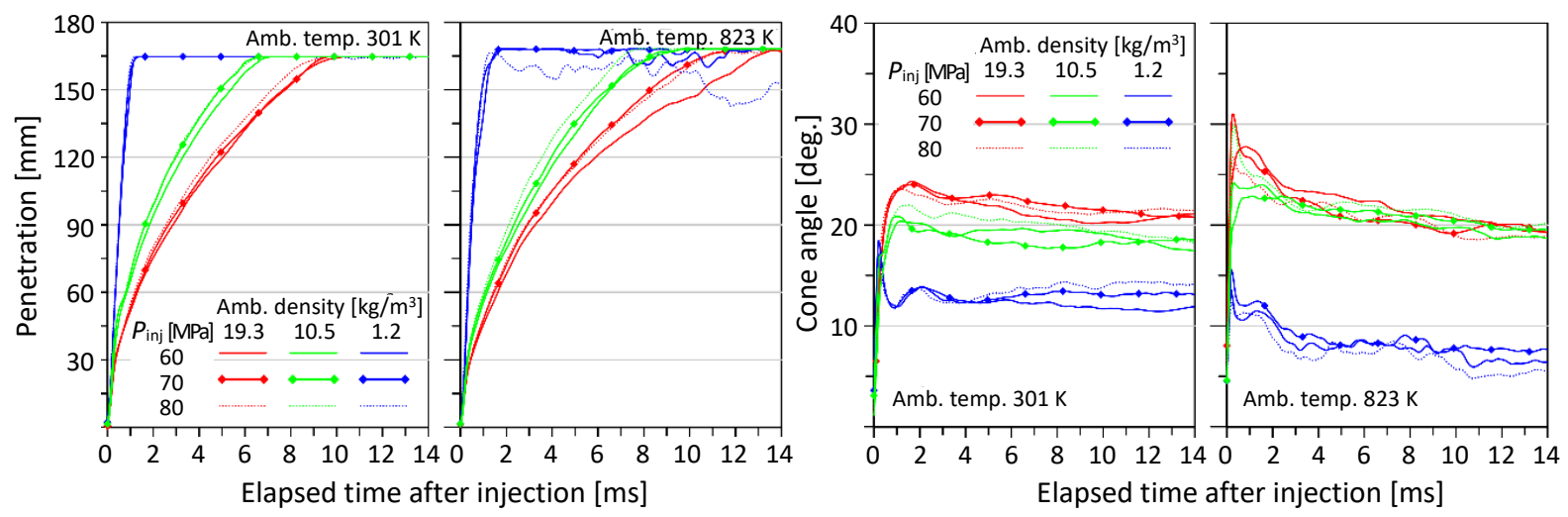

Figure 4a Spray penetration (left) and $\mathbf{4 b}$ spreading cone angle (right) versus elapsed time ASOI 
Figure 5 shows the velocity vector distribution of the ambient air obtained by PIV. In the spray measurement, the PIV analysis was performed only on the left side of the well-lit spray. It can be noticed that there are exclusion flows that spread radially around the tip of the spray, and while they wrap around, an accompanying flow that flows into the spray is generated on the side surface of the spray. Under the same conditions of density and injection pressure, the spray in the evaporation condition is slightly smaller and stronger exclusion flow generated. This indicates that, in the evaporation condition, the fuel vapor is contained in the spray, so that the momentum exchange is more positive between the spray tip and the extruded ambient air, and that the state transitions to a state close to a steady gas jet.

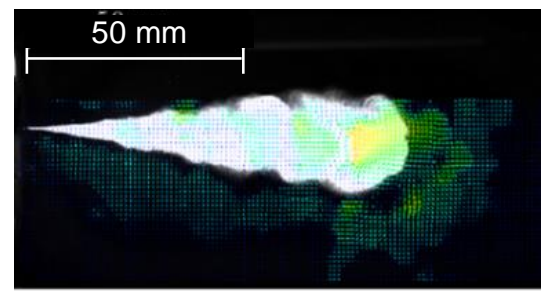

$\rho_{\mathrm{a}}=10.5 \mathrm{~kg} / \mathrm{m}^{3}$ and $T_{\mathrm{a}}=301$

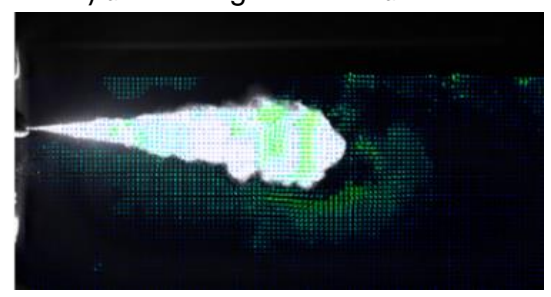

$\rho_{\mathrm{a}}=19.3 \mathrm{~kg} / \mathrm{m}^{3}$ and $T_{\mathrm{a}}=301$

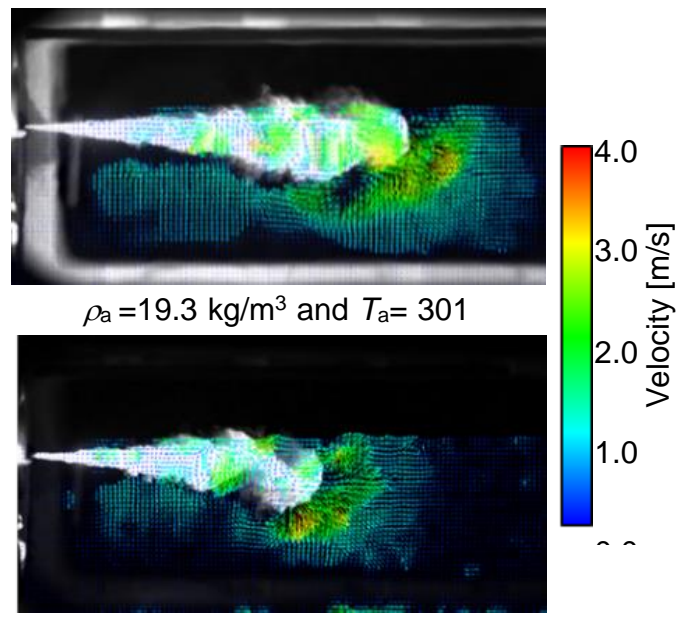

$\rho_{\mathrm{a}}=19.3 \mathrm{~kg} / \mathrm{m}^{3}$ and $T_{\mathrm{a}}=823$

Figure 5 Flow field of surrounding air at $2.5 \mathrm{~ms} \mathrm{ASOI}$ at $80 \mathrm{MPa}$ injection pressure

From Figure 6, with the spray development, the introduced mass flux in the both CS and ES increases in proportion to the time from injection. However, the introduced mass flux at the $\mathrm{CS}$ reaches 3 to 4 times that of the ES. Under evaporation conditions, the diameter of the ES decreases and the surface area decreases, so the introduced mass at the ES decreases, while at the CS, with the spray development and the evaporation progress, the maximum value of the introduced flux exceeds the non-evaporation condition.

illustrates the spray surface area versus time at different conditions. At very low density, the surface area has been noticed to increase sharply due to the high relative speed between the spray and the ambient. Then, increasing the ambient density led to a decrease in the contact surface area due to the less turbulent spray surface.

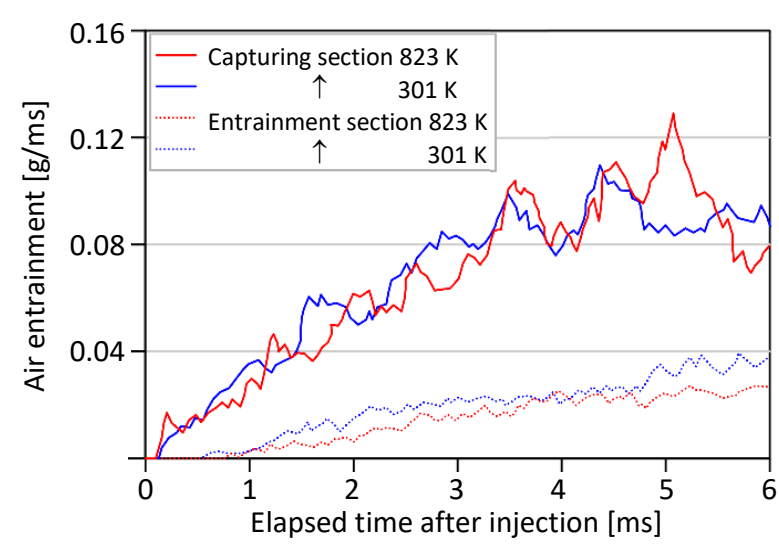

Figure 6 Sectional air entrainment rate versus time

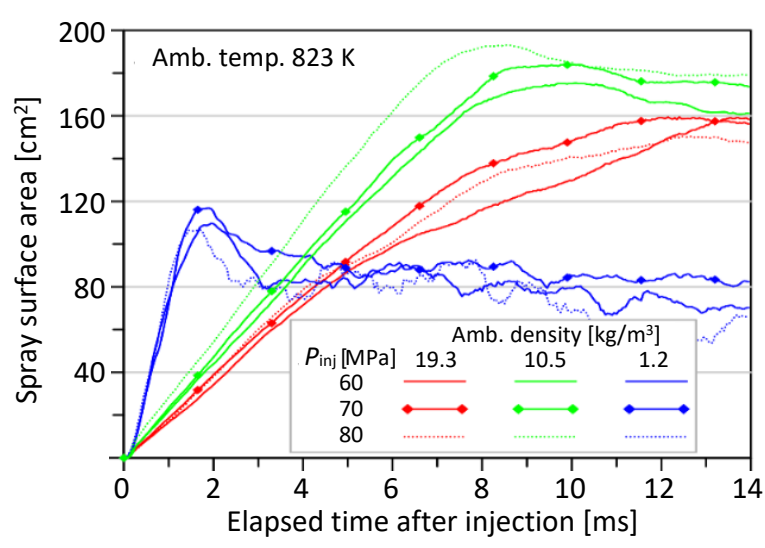

Figure 7 spray surface area versus time 
Figure 8 shows the air entrainment rate versus time and the total introduced mass versus time under different injection pressure and ambient conditions. As can be seen from Figure $\mathbf{8} \mathbf{a}$ there is no significant impact of injection pressure or ambient density on the air entrainment rate because the spray stretches quickly which increases the surface area. It was observed that the total mass of the ambient air introduced slightly increased as the injection pressure increased at the same ambient density as shown in Figure $\mathbf{8 b}$. In general, increasing the injection pressure to promote evaporation, increasing the atmospheric temperature, and increasing the atmospheric density lead to a decrease in the introduced mass in ES and an increase in the maximum value in CS. It was concluded that the influence of injection conditions and atmosphere conditions on the introduction of atmosphere is minor.

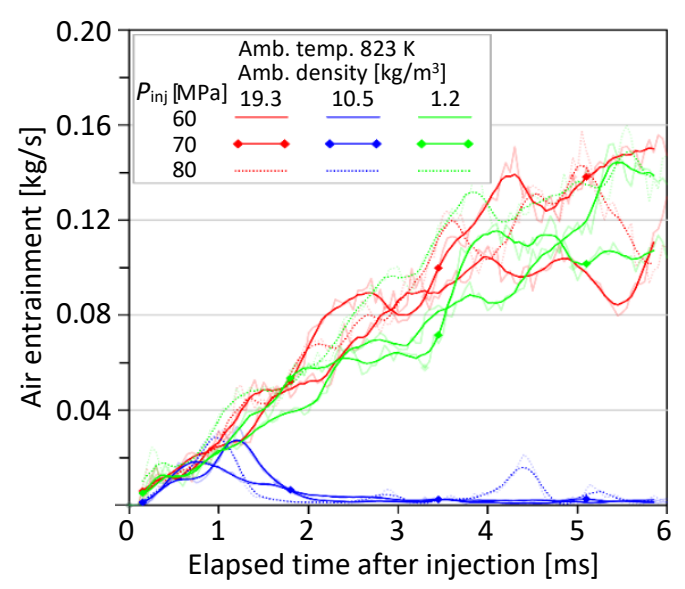

a

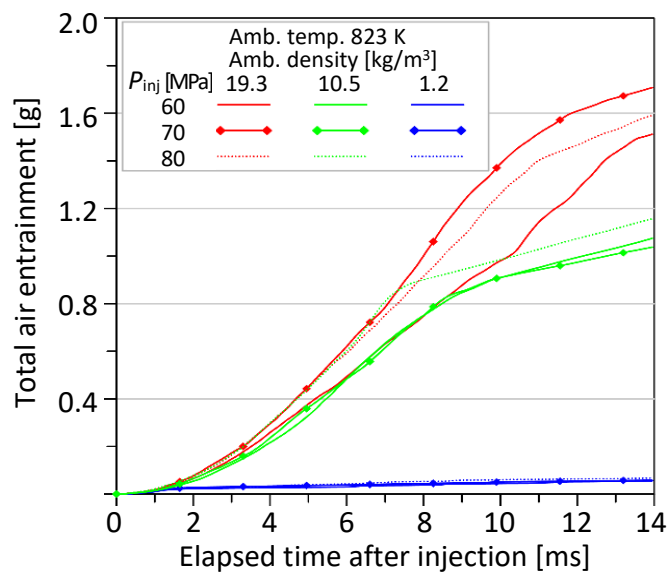

b

Figure 8 Air entrainment rate and total air entrainment respect to time

\section{CFD Results and discussion}

Using the CFD code CONVERGE, the spray simulation was performed under the same conditions as in the experiment. The spray model is the Discrete Droplet Model (DDM), the breakup model is the KH-RT model, the collision model is the NTC collision model, the evaporation model is the Frossling model, and turbulence is the RNG k- $\varepsilon$ model. The injection hole is $4 \mathrm{~mm}$ below the upper surface of the cylinder, and the mesh size inside the truncated cone with a diameter of $10 \mathrm{~mm}$ at the injector and a spread angle of 24 degrees is uniformly minimized at $0.5 \mathrm{~mm}$, and the outer diameter is $100 \mathrm{~mm}$ and the height is $200 \mathrm{~mm}$.

Also, the marker gas is injected at the position $h=10$ and $70 \mathrm{~mm}$ from the upper end of the container on the central axis of the container, and then air flow is tracked by changing in the concentration distribution of marker gas with spray development. The spray reach range is $97 \%$ of the fuel mass. The spray boundary is determined by setting the fuel volume fraction in the cell to $0.01 \%$ or more as the threshold value.

Figure 9a shows the change over time in the velocity field around the spray with the development of the spray, and Figure $9 \mathrm{~b}$ shows the spray contour based on the above definition and the vector display that reflects only the flow direction of the atmosphere. At the initial stage of injection, there is a strong flow immediately after the injection hole and at the tip of the injection hole. It is also pointed out that the flow velocity in the opposite direction to the spray from the rear end of capturing section to the upstream entrainment section. It is also the predicted flow velocity around the spray is about twice as large as the PIV measurement result, but less than $1 / 10$ of the spray progress rate, which confirms that there is air introduction from the spray tip by the relative velocity. 


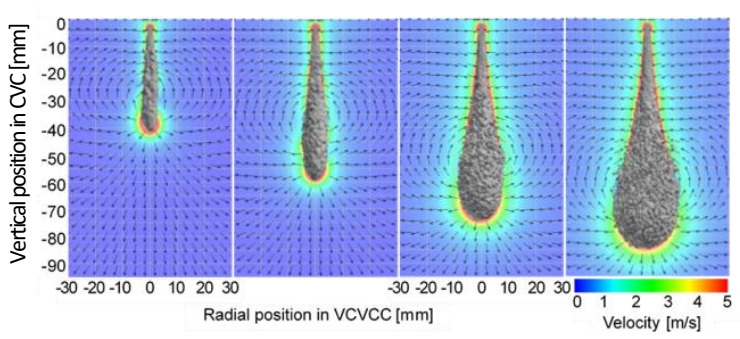

a

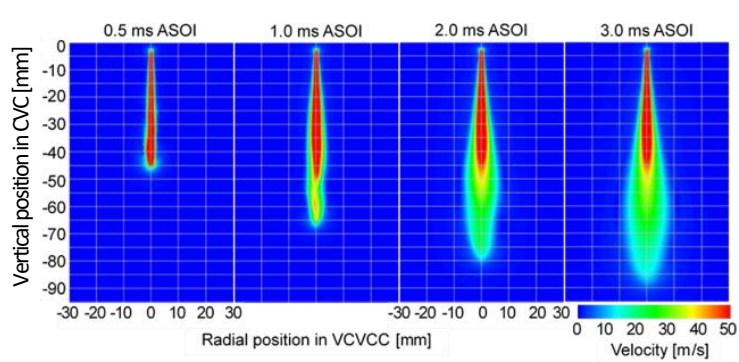

b

Figure 9 Flow velocity distribution in the spray over time $\left(P_{\mathrm{inj}}=60 \mathrm{MPa}\right)$.

Figure 10a shows the process of introducing the marker gas into the spray when the injection position $h=-10 \mathrm{~mm}$, with the mass fraction of the marker gas superimposed on the spray contour. The spray reaches the injection position just before $0.2 \mathrm{~ms} \mathrm{ASOI}$, then proceeds through the marker gas, and is introduced along the spray core until $0.5 \mathrm{~ms}$ ASOI exceeding the split distance (40 to $45 \mathrm{~mm}$ ) and reaches the spray tip.

In this way, the atmosphere existing in front of the spray at the initial stage of spraying is introduced linearly into the spray along the accompanying flow on the spray surface.

It is known that the droplets at the tip of the spray with remarkable deceleration are updated by the subsequent spray droplets with higher speed, but even in this calculation example, the marker gas starts from around the spray center axis after $2.0 \mathrm{~ms}$ ASOI. It has moved to the outer ring of the spray tip.

Figure 10b shows the introduction process when the injection position $h=-70 \mathrm{~mm}$. The arrival time of the spray at the injection position is delayed to $1.6 \mathrm{~ms} \mathrm{ASOI}$, and the marker gas is deformed before it arrives due to the exclusion flow before the spray. The developed spray cannot penetrate the marker gas and proceeds in a state where the marker gas is deformed into a horseshoe shape and attached to the front part of the spray.

However, at $2.0 \mathrm{~ms} \mathrm{ASOI}$, some of the deformed marker gas penetrates into the spray, and at $3.0 \mathrm{~ms} \mathrm{ASOI}$, the whole is present in the spray. These processes are similar to the introduction of atmosphere in CS, but the measurement results show that the introduction of atmosphere in CS is observed from the initial stage of injection, and further study is required.

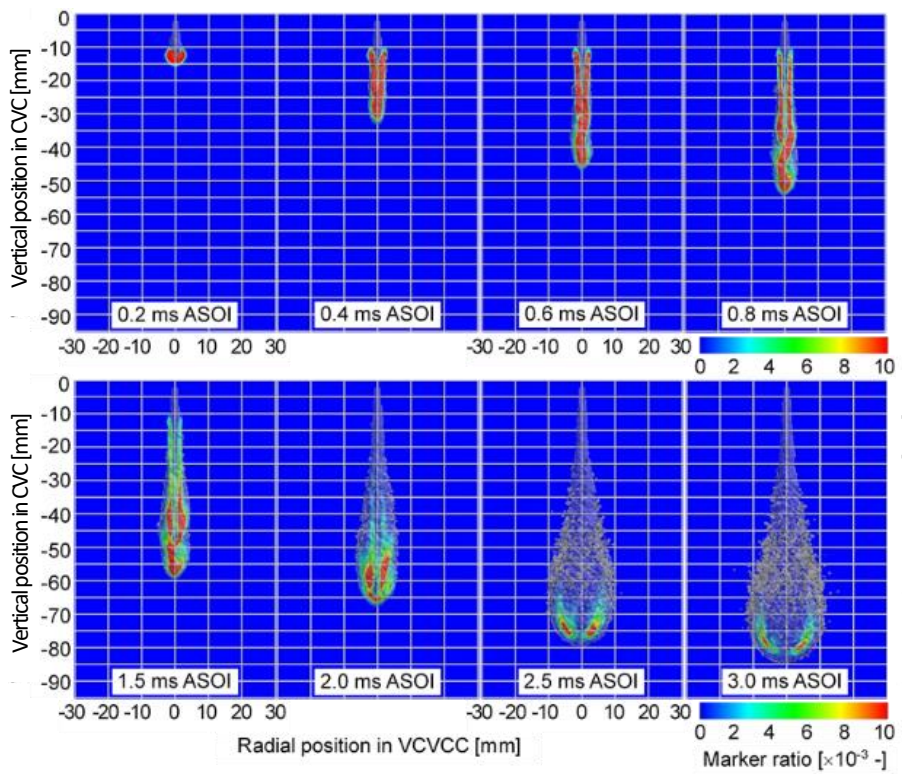

a marker gas position $h=-10 \mathrm{~mm}$

Figure 10 Mass fraction distribution of marker gas around a spray. 


\section{Conclusions}

In the recent research work, regarding the diffusion combustion used in diesel engines, the development of spray, which is the mixing process of fuel and air, and the air entrainment process are observed and injected by combining time-series PIV and various imaging methods. The following conclusions were obtained:

- Since the fuel gas generated by evaporation exists in the high temperature air, the surrounding air is strongly pushed out, so the deceleration of the spray tip also increases due to the reaction, and the reach of the spray tip is shorter than in the non-evaporation condition. - With the spray development, the introduced mass flux in the both section increases in proportion to the time from injection, and the introduced mass flux at the CS reaches 3 to 4 times that of the ES.

- The mass of the air introduced into the spray slightly increased due to the increase in injection pressure.

- In general, increasing the injection pressure to promote evaporation, increasing the atmospheric temperature, and increasing the atmospheric density lead to a decrease in the introduced mass in ES and an increase in the maximum value in CS. It was concluded that the influence of injection conditions and atmosphere conditions on the introduction of atmosphere is minor.

- Numerical predictions show that there is a qualitative difference in the introduction process of the atmosphere before spraying between the early and late stages of injection, and that the atmosphere introduced in the early stage tends to be transferred forward along the spray nucleus.

\section{References}

[1] Zhang, J. et al., 2019, Applied Energy, 252(June), pp. 113428.

[2] Xia, J. et al., 2020, Energy Conversion and Management, 205(October 2019), pp. 112397.

[3] Shi, Z. et al., 2020, Applied Energy, 262(October 2019), pp. 114552.

[4] Kannaiyan, K., Sadr, R., 2017, Experimental Thermal and Fluid Science, 87, pp. 93103.

[5] Yu, Y. et al., 2020, International Journal of Hydrogen Energy, 45(17), pp. 10592-10601.

[6] Wakuri, Y. et al., 1960, Bull JSME, 3(9), pp. 123-30.

[7] Hiroyasu, H., Arai, M., 1990, SAE technical paper, pp. 900475. 